Mustafa M Al-Sultan BDS, MSc (Lec.)

\section{Stability Evaluation of Micro-Screw Im- plant in Cases Given a Bone Inducing Substances "An Experimental in Vivo Study"}

\author{
Dept of Pedod, Orthod, and Prev Dentistry \\ College of Dentistry, University of Mosul
}

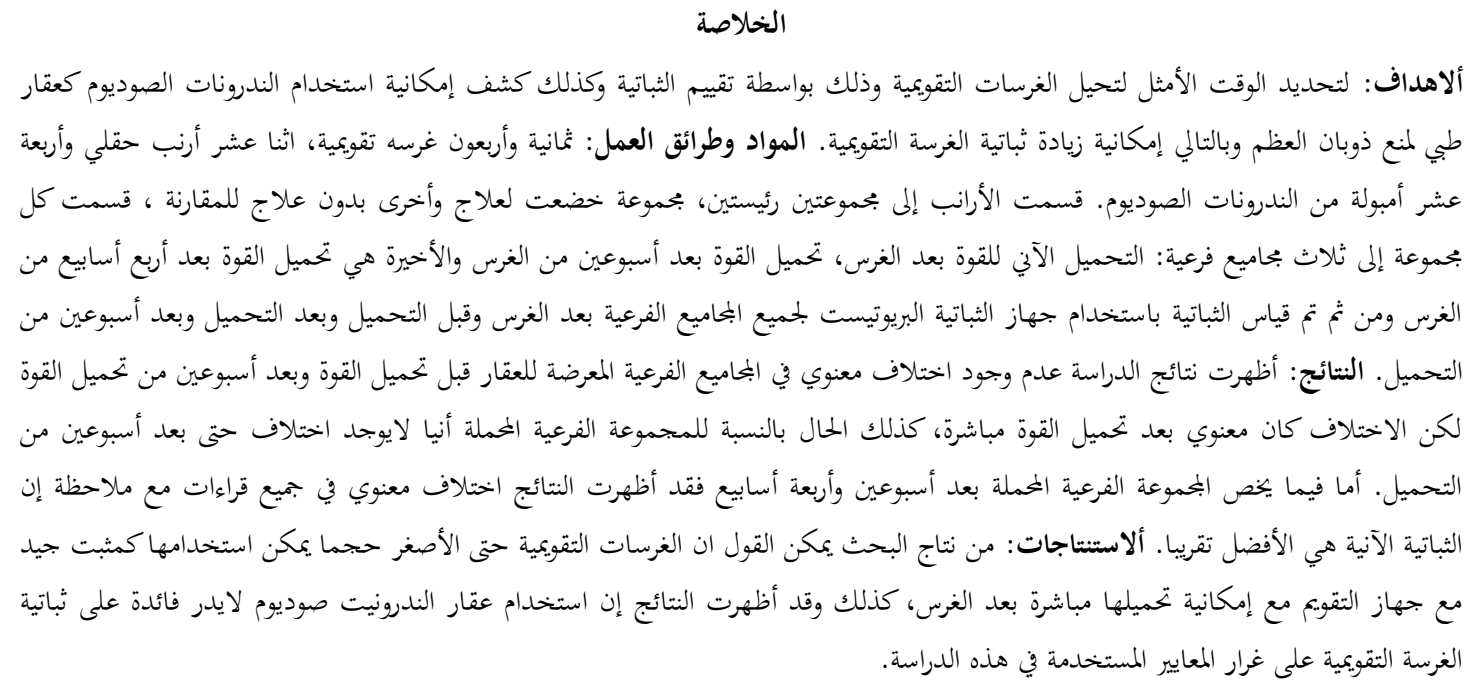

\begin{abstract}
Aims: The present study aimed to investigate the desirable loading time of micro-screw implant by stability evaluation and detecting the possibility of using alendronate sodium to increase the stability. Materials and methods: Forty eight micro-screw implant, twelve adult rabbits and fourteen alendronate sodium ampoules were used in this study, the rabbits were divided into two main groups, treated and control group, which further subdivided into three subgroups. Eight micro-screw implant instilled in tibiaes of each subgroup just six of them used for test the remaining cancelled, the stability test down using the periotest. These subgroups were nominated according to the loading times which are immediate loading, loading after two weeks and loading after four weeks with stability measured after instillation, before and after loading and two weeks after loading. Results: No significant differences between subgroups before loading and after two weeks of loading but significant after loading. For immediately loaded treated subgroup no significant differences between immediate loading and two weeks after loading. For two and four weeks treated subgroup a significant difference in stability between immediate instillation and after loading. Conclusions: Micro-screw implant even smaller diameter could be used as a fixed anchorage in orthodontics and possibly could be loaded safely from time of immediate instillation, further the use of alendronate sodium add no benefit to increase stability according to the criteria used in this study.
\end{abstract}

Key words: Stability, Micro-screw implant, Bone inducing substances.

Al-Sultan MM. Stability Evaluation of Micro-Screw Implant in Cases Given a Bone Inducing Substances "An Experimental in Vivo Study. Al-Rafidain Dent J. 2013; 13(1): 136-146.

Received: 28/11/2011 Sent to Referees: 28/11/2011

Accepted for Publication: 29/1/2012

\section{INTRODUCTION}

Good anchorage control is one of the prerequisites of successful orthodontic therapy. Recently, micro-screw implant have been proven to be useful in establishing absolute anchorage without the use of extra-oral appliances, add to their flexibil- ity in choosing implant locations, lower medical costs, simpler implant surgery, and lower degrees of discomfort after implantation compared with traditional dental implants. ${ }^{(1,2)}$ However, these miniscrews loosen easily and their failure rate may be as high as $25 \%$. $^{(3,4)}$ 
The stability is of two components: Primary stability which is established from the mechanical lock between the micro-screw implant surface and bone. ${ }^{(5)}$ It is depends on the thickness and integrity of the cortical bone. The Micro-screw implant design, and loading protocol. ${ }^{(5,6)} \mathrm{Sec}$ ondary stability is achieved through continuous bone remodeling around the Micro-screw implant, leading to osseointegration (increasing bone density). ${ }^{(7,8)}$ Which is a critical determinative factor of the performance of endosseous implant. ${ }^{(9,10)}$ Healing time, has a considerable impact on the osseointegration. ${ }^{(11-14)}$

Some studies showed increased bone marrow density (BMD) of $4 \%$ to $8 \%$ with the use of alendronate sodium, Boneresorption inhibitor. Osteoclast inhibition is the primary reason for this phenomenon. (15) There are no studies comparing the effect of systemic administration of alendronate on dental implant osseointegration. In this study, a rabbit tibia model was used to examine the effects of alendronate as osteoclast inhibitors at different loading and healing times on mechanical stability. The present study aimed to investigate the desirable loading time of micro-screws by stability evaluation.

\section{MATERIALS AND METHODS}

Fourty eight commercially available self-drilling titanium micro-screw implants (Abso-anchor, Dentos Inc, Daegu, Korea), twelve adult female rabbits and fourteen alendronate sodium ampules (Diamond Pharma-Damascus-Syria under license of ABC Farmaceutici-Torino-Italy) for intra muscular injection were used in this study. Each micro-screw implant was selected from the same series, with the same length, diameter and similar shape. measuring $1.3 \mathrm{~mm}$ in diameter and $5 \mathrm{~mm}$ in length, the rabbits were 12 months old (each weighting $2 \mathrm{~kg}$ ) and the drug Pharmacologic class; Bisphosphonate, Therapeutic class: Bone-resorption inhibitor, its Action is impeding bone resorption by inhibiting osteoclastic activity, absorbing calcium phosphate crystal in bone, and directly blocking dissolution of hydroxyl apatite crystal of bone.

All micro-screws and rabbits were divided into two groups; the first untreated group (control group) is the plane group (p) which further subdivided into three subgroups, which are, the immediate loading plane subgroup (0WP), 2-week healing plane subgroup (2WP) and 4-week healing plane subgroup (4WP) while the second group is the treated group $(\mathrm{T})$ which also subdivided into three subgroups, the immediate load treated subgroup(0WT), 2week healing treated subgroup (2WT) and 4 week treated subgroup (4WT). The drugs given to each rabbit intra muscularly $(0.3 \mathrm{ml})$ for fourteen days before Microscrew implant instillation (which is just one of the multiple courses recommended, to human, by the manufacturer). There were 8 micro-screws in each subgroup six of them tested and two cancelled due to failure like fracture of screw during driving and some shows bone crack at penetration of screw. There were two rabbit in each of the six subgroups. These six subgroups may encounter the three pathological periods of bone healing after the instillation of the micro-screw implant, that is, the traumatic period, granulation period, and callus period, respectively. ${ }^{(16)}$ The micro-screw implant were instilled in the tibiae of each animal, all the microscrew implant were then tested for their stability using the periotest machine (Medizintechnik Gulden e.k. Eschenweg 3, 64397 Modautal, Germany) (Figure 1) 


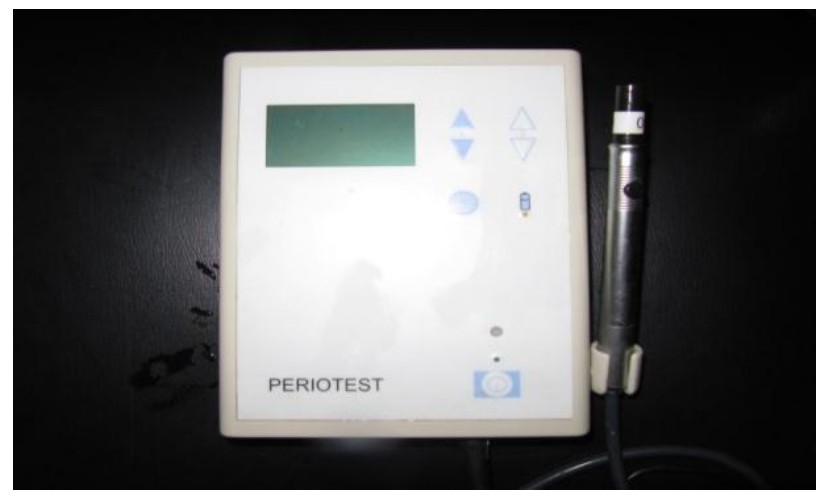

Figure (1): Periotest machine

Which is specified for testing the stability of any structure inserted in the bone and also for natural tooth structure. The periotest scale extend from -8 to +50 , the lower the value, the greater is the stability with the periotest value range from -8 to 0 this mean a good osseointegration and implant can be loaded, +1 to +9 values mean clinical examination is required and loading is not yet possible, more than +9 mean that the implant must not be loaded.

\section{Surgical Procedures}

All surgeries were performed under sterile conditions in an animal operation room. The animals were anesthetized intramuscularly with a combination of ketamine (44 mg/kg of body weight) and xylazine (7 $\mathrm{mg} / \mathrm{kg}$ of body weight). The local nerve supplies of the internal surface of the tibia were further blocked with $0.5 \mathrm{ml}$ of $2 \%$ Lidocaine (Figure 2).

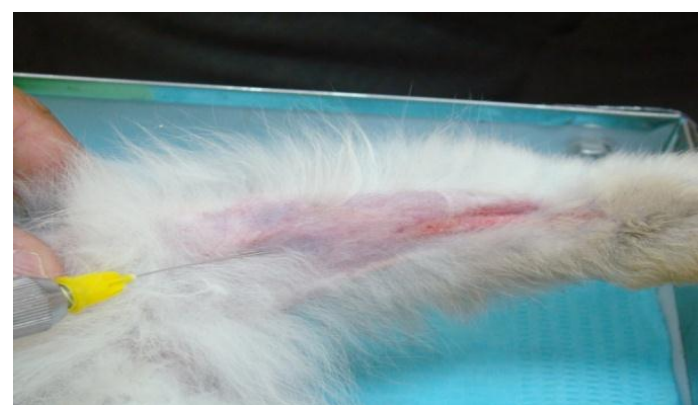

Figure (2): the local nerve further anaesthetized with $0.5 \mathrm{ml} 2 \%$ lidocaine

The tibiae body was exposed by incisions through the skin, fascia, and periosteum (Figure 3)

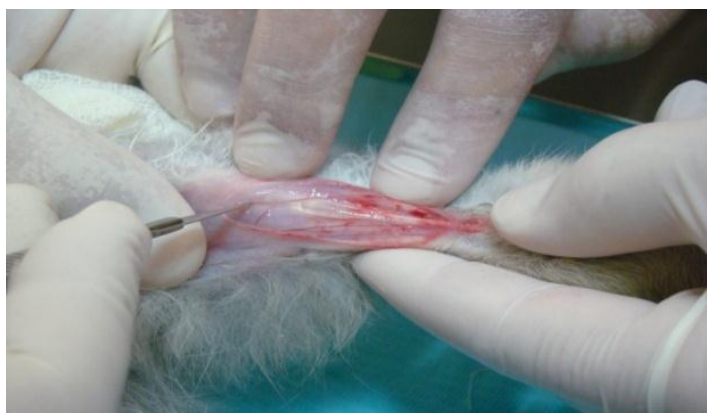

Figure (3): incisions through the skin, fascia and periostium

The cortical bone of the preparation sites was penetrated using a $0.6 \mathrm{~mm}$ diameter guide drill under profuse irriga- tion (Figure 4). After pilot drilling, the Micro-screw implants were placed using a manual driver (Figure 5). 


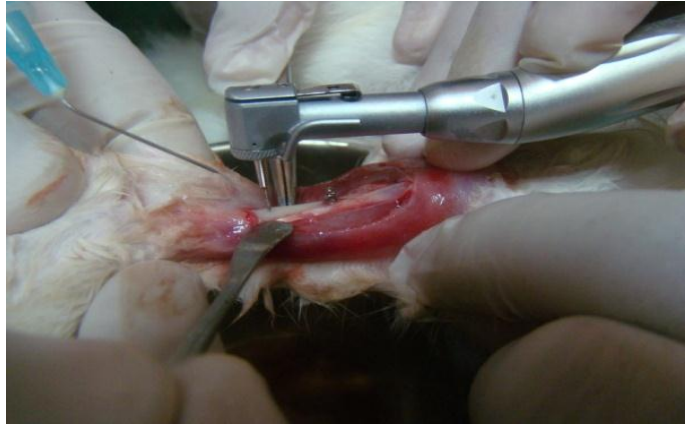

Figure (4): guide drill under perfused irrigation

All Micro-screw implants were allowed to penetrate the first cortical layer and going through the woven bone only( not penetrating the opposing cortical plate). The loading involved nickeltitanium closed-coil springs (Denturum)

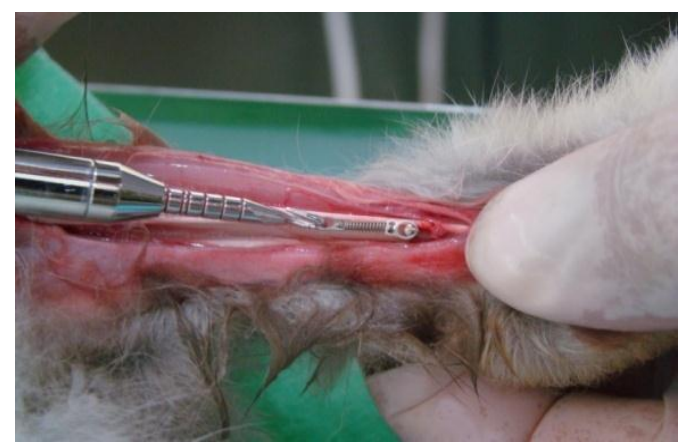

Figure (6a): application of coil spring

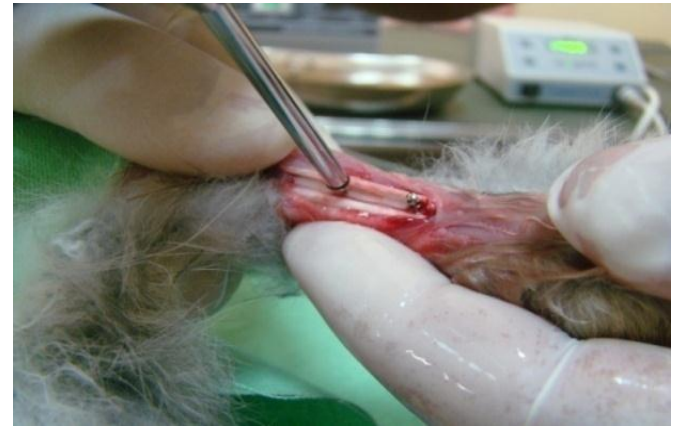

Figure (5): manual drilling of Micro-screw

were applied to the coronal portion of the Micro-screw implants with $100 \mathrm{~g}$ of force using tension gauge (Anthogyr company, France) (Figure $6 a, b)$. the mucoperiosteum and muscle were sutured in separate layers using absorbable sutures (Figure 7).

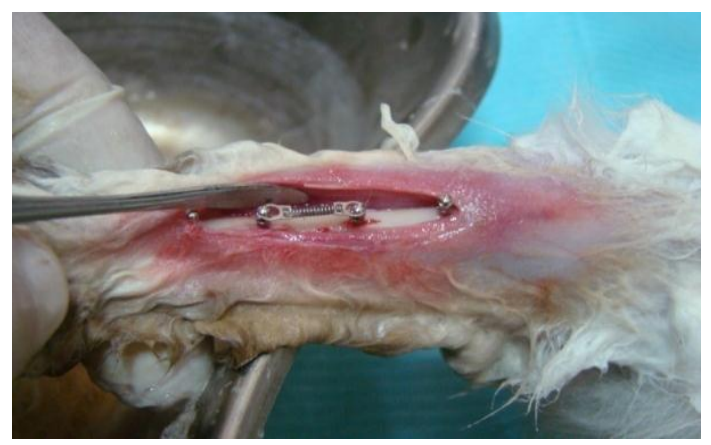

Figure (6b): application of coil spring

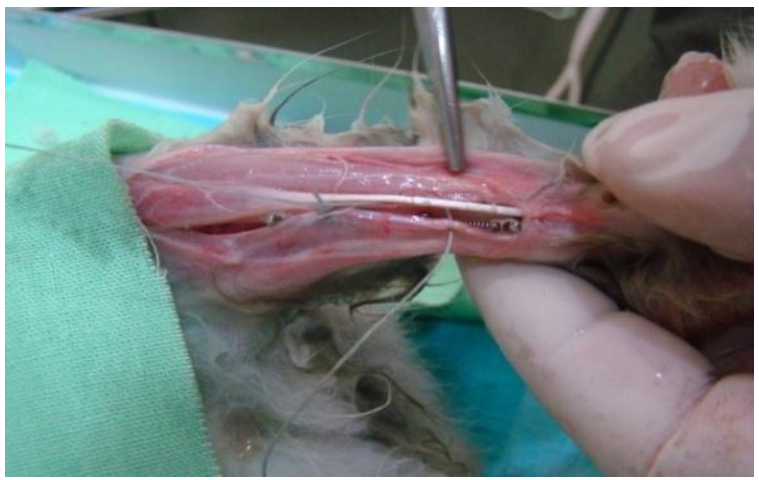

Figure (7): suturing the tissue layers with absorbable suture

The stability testing involve the following: In the 0WP subgroup the implant were tested for their stability immediately after instillation (figure 8) then after loading (figure 9) the test repeated after 2 week healing period. For the $2 \mathrm{WP}$ subgroup; the stability tested immediately after micro-screw implant instillation then the specimen left 2 week for healing then the surgical site opened again. The test repeated again before loading then after loading each rabbit then lifted for healing period of two week which then scarified. 


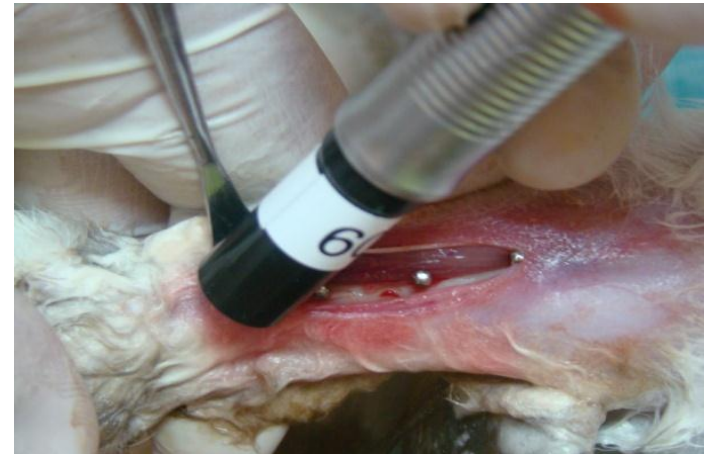

Figure (8): stability test before loading

The stability again tested. For the 4WP subgroup; the stability tested after instillation of the micro-screw implant then lifted for healing period of 4 week after that the surgical site opened again and the stability tested before loading and after loading then each rabbit lifted for healing period of 2 weeks, which then scarified and the sta-

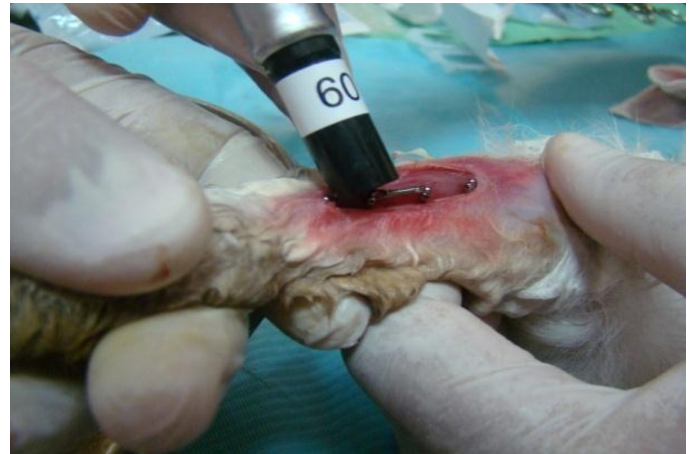

Figure (9): stability test after loading

bility tested again.

\section{RESULTS}

The statistical analysis showed differences, but not significant between subgroups 0WT, 2WT and 4WT before loading Table (1), Figure (10).

Table (1): ANOVA statistical test for treated subgroups before loading

\begin{tabular}{llllll}
\hline & Sum square & Degree of freedom & Main square & F value & $\boldsymbol{P}$ value \\
\hline Between group & 0.048 & 2 & 0.024 & 3.116 & 0.074 \\
Within group & 0.115 & 15 & 0.008 & & \\
Total & 0.163 & 17 & & & \\
\hline
\end{tabular}

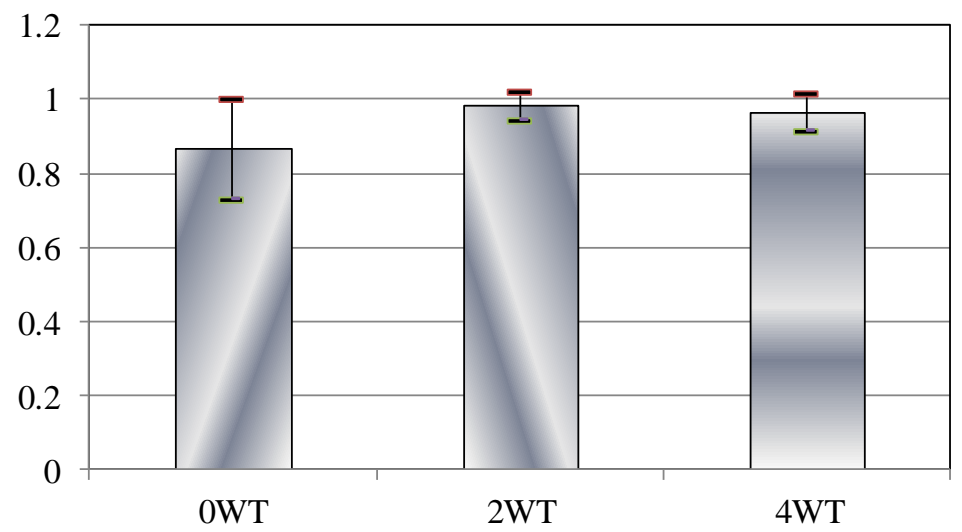

Figure (10): Histogram of Duncan statistical test between treated subgroups before loading.

After loading no significant differences between 2WT and 4WT, but significant for 0WT Table (2), Figure (11) while on comparing the results between groups after a healing periods of 2 week.

Table (2): ANOVA statistical test for treated subgroups after loading

\begin{tabular}{llllll}
\hline & Sum square & Degree of freedom & Main square & F value & $\boldsymbol{P}$ value \\
\hline Between group & 0.063 & 2 & 0.032 & 11.400 & 0.001 \\
Within group & 0.042 & 15 & 0.003 & & \\
Total & 0.105 & 17 & & & \\
\hline
\end{tabular}




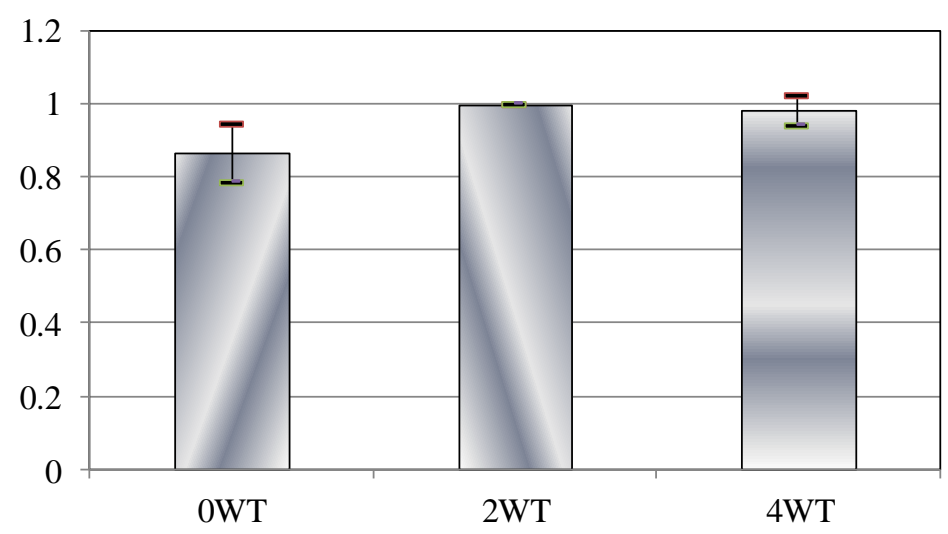

Figure (11): Histogram of Duncan statistical test between treated subgroups after loading

The result showed no significant differences between them Table (3), Figure (12).

Table (3): ANOVA statistical test for treated subgroups after healing period followed loading

\begin{tabular}{llllll}
\hline & Sum square & Degree of freedom & Main square & F value & $\boldsymbol{P}$ value \\
\hline Between group & 0.043 & 2 & 0.022 & 3.197 & 0.070 \\
Within group & 0.102 & 15 & 0.007 & & \\
Total & 0.142 & 17 & & & \\
\hline
\end{tabular}

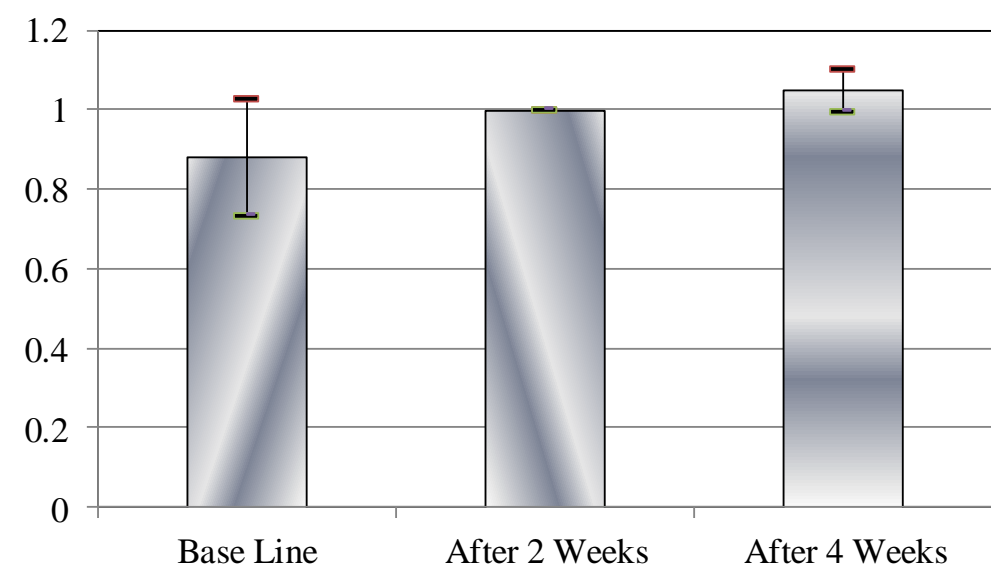

Figure (12): Duncan statistical test for two weeks treated subgroups.

On comparing the results of stability for OWT subgroup before (BL) and 2 weeks healing after loading (TWAL) also after immediate loading (IL) and 2 weeks healing after loading no significant differences observed Table $(4,5)$.

Table (4): Statistical T test for stability of unloaded micro-screw implant and two weeks after loading

\begin{tabular}{llllll}
\hline & Mean & Standard deviation & T test & Degree of freedom & $\boldsymbol{P}$ value \\
\hline BL & 0.8667 & 0.13663 & 0.894 & 10 & 0.392 \\
TWAL & 0.9333 & 0.12111 & & & \\
\hline
\end{tabular}

Table (5): Statistical T test for stability of loaded micro-screw implant and two weeks after loading

\begin{tabular}{llllll}
\hline & Mean & Standard deviation & T test & Degree of freedom & $\boldsymbol{P}$ value \\
\hline IL & 0.8667 & 0.08165 & 1.118 & 10 & 0.290 \\
TWAL & 0.9333 & 0.12111 & & & \\
\hline
\end{tabular}


For 2WT subgroup a significant differences had been shown in stability among immediate instillation, loading after two weeks and 2 weeks after loading Table (6) Figure (13), for 4WT subgroup also significant differences among immediate instillation, loading after 4 weeks and 2 weeks after loading Table (7) Figure (14).

Table (6): ANOVA statistical test of stability differences among immediate instillation, loading after 2 weeks and 2 weeks after loading

\begin{tabular}{llllll}
\hline & Sum square & Degree of freedom & Main square & F value & $\boldsymbol{P}$ value \\
\hline Between group & 0.088 & 2 & 0.044 & 5.338 & 0.018 \\
Within group & 0.123 & 15 & 0.008 & & \\
Total & 0.211 & 17 & & & \\
\hline
\end{tabular}

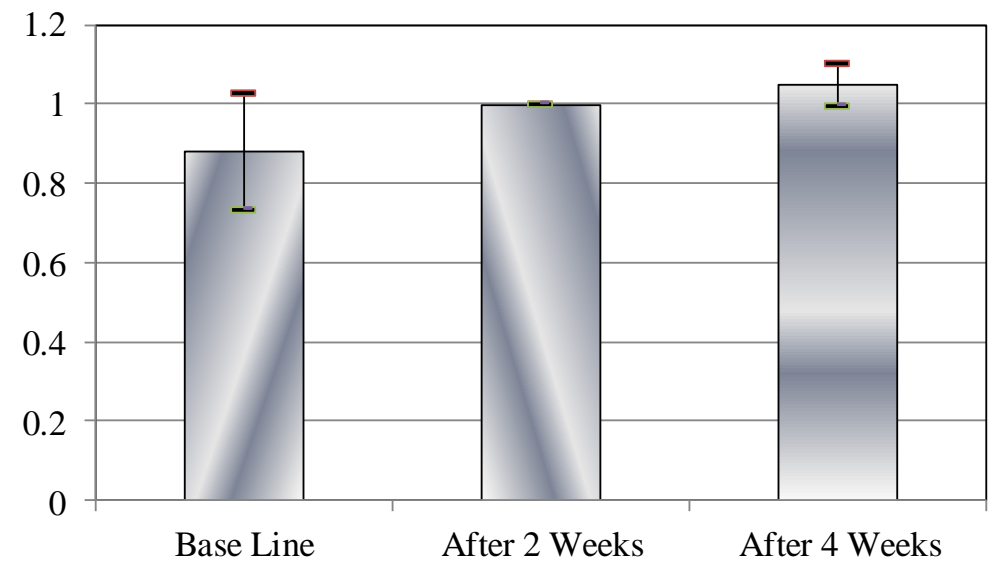

Figure (13): Duncan statistical test for two weeks treated subgroups.

Table (7): ANOVA statistical test of stability differences among immediate instillation, loading after 4 weeks and 2 weeks after loading

\begin{tabular}{llllll}
\hline & Sum square & Degree of freedom & Main square & F value & $\boldsymbol{P}$ value \\
\hline Between group & 0.063 & 2 & 0.032 & 6.196 & 0.011 \\
Within group & 0.077 & 15 & 0.005 & & \\
Total & 0.140 & 17 & & & \\
\hline
\end{tabular}

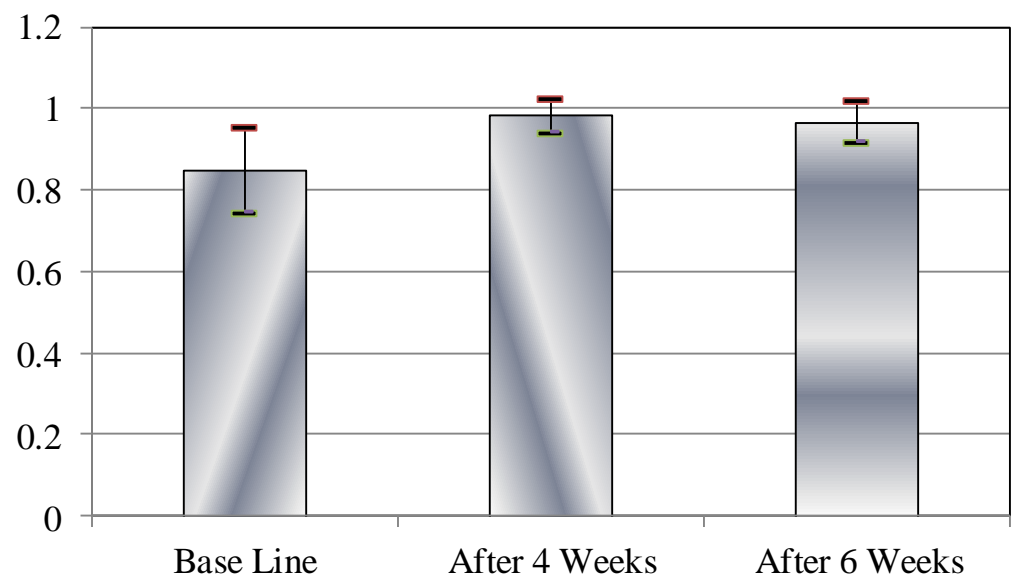

Figure (14): Duncan statistical test for four weeks treated subgroups. 
For the plane subgroups, a significant difference of 0WP subgroup from both 2WP and 4WP subgroups which showed no significant differences. This is before and after loading (Table 8,9 ) but after a healing period of two weeks no significant differences observed (Table 10).

Table (8): Duncan statistical test for the control sample of the three subgroups after loading

\begin{tabular}{lccc} 
& Mean & Standard deviation & Duncan \\
\hline 0WP & 0.7167 & 0.16021 & $\mathrm{~A}$ \\
2WP & 1.0 & 0.0 & $\mathrm{~B}$ \\
4WP & 0.9667 & 0.05164 & $\mathrm{~B}$ \\
\hline
\end{tabular}

Table (9): Duncan statistical test for the control sample of the three subgroups before loading

\begin{tabular}{lccc}
\hline & Mean & Standard deviation & Duncan \\
\hline 0WP & 0.60 & 0.12649 & $\mathrm{~A}$ \\
2WP & 1.0 & 0.0 & $\mathrm{~B}$ \\
4WP & 0.90 & 0.06325 & $\mathrm{~B}$ \\
\hline
\end{tabular}

Table (10): Duncan statistical test for the control sample of the three groups after after loading

\begin{tabular}{lccc}
\hline & Mean & Standard deviation & Duncan \\
\hline 0WP & 0.9167 & 0.04082 & $\mathrm{~A}$ \\
2WP & 0.9833 & 0.09832 & $\mathrm{~A}$ \\
4WP & 0.8833 & 0.07528 & $\mathrm{~A}$ \\
\hline
\end{tabular}

On comparing the results of stability for OWP subgroup before loading and after 2 weeks of loading also after immediate loading and after 2 weeks a significant differences observed Table $(11,12)$

Table (11): Statistical T test of immediately instilled screw and two weeks after loading

\begin{tabular}{llllll}
\hline & Mean & Standard deviation & T test & Degree of freedom & $\boldsymbol{P}$ value \\
\hline BL & 0.6 & 0.12649 & 5.836 & 10 & $0.000^{*}$ \\
I L & 0.9167 & 0.04082 & & & \\
\hline
\end{tabular}

*significant difference

Table (12): Statistical test of loaded screw and two weeks after loading

\begin{tabular}{llllll}
\hline & Mean & Standard deviation & T test & Degree of freedom & $\boldsymbol{P}$ value \\
\hline BL & 0.7167 & 0.16021 & 2.963 & 10 & $0.014^{*}$ \\
TWAL & 0.9167 & 0.04082 & & & \\
\hline
\end{tabular}

*significant difference

For 2WP subgroup a significant difference in stability of immediately instilled micro-screw implant from stability of loading after 2 weeks and those lifted for 2 weeks after loading (Table 13).

Table (13): Duncan statistical test for the two weeks control subgroup

\begin{tabular}{cccc}
\hline & Mean & Standard deviation & Duncan \\
\hline 0WP & 0.8500 & 0.05477 & $\mathrm{~A}$ \\
$\mathbf{2 W P}$ & 1.0 & 0.0 & $\mathrm{~B}$ \\
$\mathbf{4 W P}$ & 0.9833 & 0.09832 & $\mathrm{~B}$ \\
\hline
\end{tabular}

for the 4WP subgroups a nearly significant differences in stability reading in the three times intervals, since time of imme- diate instillation, 4 weeks then loading and 2 weeks after loading (Table 14). 
Table (14): Duncan statistical test for the four weeks control subgroup

\begin{tabular}{lccc}
\hline & Mean & Standard deviation & Duncan \\
\hline 0WP & 0.7833 & 0.1472 & $\mathrm{~A}$ \\
2WP & 0.9667 & 0.05164 & $\mathrm{~B}$ \\
4WP & 0.8833 & 0.07528 & $\mathrm{AB}$ \\
\hline
\end{tabular}

\section{DISCUSSION}

No significant literature exists comparing the effect of systemic bisphosphonate therapy on endosseous implant osseointegration. Some studies have concentrated on locally applying bisphosphonates to implant surfaces and then measuring the bone response. Statistically significant increases in bone density and bone formation occurred with the alendronatecoated implants. ${ }^{(17)}$

This study showed that in general no significant differences between the treated and plane subgroups according to the treatment course given in that the stability measurements of the treated subgroups before loading of the micro-screw implants were different, although not significant which larger in 0WT subgroup. This probably due to the effect of primary stability, then 4WT subgroup may represent the beginning of increase bone density around the micro-screw implant and the lower stability of 2WT subgroup could be due to the process of bone remodeling (resorption and apposition) which ordinarily occur as a healing process may affect its stability, unlike the control group which showed a significant difference. Same difference after loading but significant for 0WT subgroup and not for 2WT and 4WT subgroups. For 0WT subgroup, it is probably the result of increase fitness (a result of added tension of loading) and add to the influence of primary stability, but for 2WT subgroup as described above it may be due to the remodeling process and for $4 \mathrm{WT}$ subgroup, here the effect of loading may do breaking of initial formed bone attachment, this result same that of control group.

The stability measurement of the three treated subgroups after a healing periods of two weeks for the loaded micro-screw implant showed a differences, but not significant which higher for OWT subgroup which could be due to the effect of primary stability add to spring tension from zero to two weeks period then 4WT subgroup, which probably be due to increase bone formation around the screw due to healing period of 6 weeks that increase its fitness, this come in accordance with the result of control subgroup.

The stability measurement for OWT subgroup showed no significant differences from time of instillation of screw till loading then 2 weeks after loading. This could be the result of a short time and still under the control of primary stability. This is not in accordance with the control subgroups. For 2WT subgroup, a significant difference had been shown from time of instillation, 2 week then loading, 2 week after loading, with stability higher for the first time of instillation and this is already explained, same result for control subgroups. similar to 4WT subgroups a significant difference in mean from time of instillation, 4 week then loading, 2 week healing period after loading, although the stability mean for 4WT subgroup better than 2WT subgroup which may be due to the time factor. The screw may need time after losing the primary stability and getting the secondary one by bone cell accumulation around the screw (increase bone density or possibly osseointegration), this is also similar to those control subgroups.

In general, we notice that the initial reading of stability is higher than subsequent measurement although time factor is important that is to say with the time and progress of bone healing around the screw will probably lead to bone cell accumulation around the screw, but here the size of screw may affect the stability, because we use the smaller sort in the micro-screw implant kit. This mean that we may need a longer time for the smaller diameter to establish a good secondary stability and comparing to other studies on micro-screw all using nearly double. This size also may get no benefit of using one course of multiple course recommend by the manufacture that subjecting the patient to a multi- 
ple courses of medication is a legal point of view which even in one course and also need time which is not problem in dental implant, but for micro-screw implant is a time temporary process of nearly maximum one year so we may finish the use of the implant and still need time to finish the course of medication.

Saito ${ }^{(18)}$ suggested that orthodontic force should be loaded on the micro-screw after 18 weeks of healing. Roberts ${ }^{(19)}$ concluded that micro-screws could stand orthodontic loading of $100 \mathrm{~g}$ after 6 weeks of healing. Studies by Costa ${ }^{(20)}$ indicated that micro-screws could provide stable anchorage after 4 weeks of healing. Melsen ${ }^{(21)}$ reported that osseointegration could be observed on the immediately loaded bone-implant interface. Some clinicians suggest that some healing time is required and recommend delaying force application. ${ }^{(22)}$ Others, however, state that orthodontic force can be applied immediately after implantation. ${ }^{(23)}$

A complete understanding of this drug class and the effects on long-term implant osseointegration in humans will require further study.

\section{CONCLUSION}

According to the result of this study all the stability in different time interval are acceptable according to the stability standard criteria of the periotest prescribed before, thus micro-screw implant even smaller diameter can be used as a fixed anchorage in orthodontics and possibly can be loaded safely from immediate instillation.

\section{REFERENCES}

1. Miyawaki S, Koyama I, Inoue M, Mishima K, Sugahara T, TakanoYamamoto T. Factors associated with the stability of titanium screws placed in the posterior region for orthodontic anchorage. Am J Orthod Dentofacial Orthop. 2003; 124: 373-378.

2. Lee JS, Park HS, Kyung HM. Microimplant anchorage for lingual treatment of a skeletal Class II malocclusion. $J$ Clin Orthod. 2001;35:643-647.

3. Simon H, Caputo AA. Removal torque of immediately loaded transitional en- dosseous implants in human subjects. Int J Oral Maxillofac Implants. 2002; 17:839-845.

4. Bae SM, Park HS, Kyung HM, Kwon OW, Sung JH. Clinical application of micro-implant anchorage. $\mathrm{J}$ Clin $\mathrm{Or}$ thod. 2002; 36: 298-302.

5. Kim YK, Kim YJ, Yun PY, Kim JW. Effects of the taper shape, dual-thread, and length on the mechanical properties of mini-implants. Angle Orthod. 2009; 79: 908-914.

6. Wilmes B, Rademacher C, Olthoff G, Drescher D. Parameters affecting primary stability of orthodontic miniimplants. J Orofac Orthop. 2006; 67: 162-174.

7. Heidemann W, Terheyden H, Gerlach KL. Analysis of the osseous/metal interface of drill free screws and self tapping screws. J Craniomaxillofac Surg. 2001: 69-74.

8. Roberts WE, Helm FR, Marshal KJ, Gongloff RK. Rigid endosseous implants for orthodontic and orthopedic anchorage. Angle Orthod. 1990; 59: 247-256.

9. Ueda M, Matsuki M, Jacobsson M, et al. Relationship between insertion torque and removal torque analyzed in fresh temporal bone. Int J Oral Maxillofac Implants. 1991; 6: 442-447.

10. Motoyoshi M, Ueno S, Okazaki K, Shimizu N. Bone stress for a miniimplant close to the roots of adjacent teeth-3D finite element analysis. Int $J$ Oral Maxillofac Surg. 2009; 38: 363368.

11. Kuroda S, Yamada K, Deguchi T, Hashimoto T, Kyung HM, TakanoYamamoto T. Root proximity is a major factor for crew failure in orthodontic anchorage. Am J Orthod Dentofacial Orthop. 2007; 131: S68-S73.

12. Kim YK, Kim YJ, Yun PY, Kim JW. Effects of the taper shape, dual-thread, and length on the mechanical properties of mini-implants. Angle Orthod. 2009; 79: 908-914.

13. Wilmes B, Rademacher C, Olthoff G, Drescher D. Parameters affecting primary stability of orthodontic miniimplants. J Orofac Orthop. 2006; 67: 162-174. 
14. Wilmes B, Ottenstreuer S, Su YY, Drescher D. Impact of implant design on primary stability of orthodontic miniimplants. J Orofac Orthop. 2008; 69: 42-50.

15. Meraw SJ, Reeve CM, Wollan PC: Use of alendronate in periimplant defect regeneration. 1999; J Periodontol. 70: 151

16. Albrektsson T, Johansson C, Sennerby L. What is osseointegration? In: Worthington P, Evans JR, eds. Controversies in Oral \& Maxillofacial Surgery. Philadephia, PA: WB Saunders Company; 1994: 436-450.

18. Saito S, Sugimoto N, Morohashi T, et al. Endosseous titanium implants as anchors for mesiodistal tooth movement in the beagle dog. Am J Orthod Dentofacial Orthop. 2001; 18: 601-607.

19. Roberts WE, Marshall KJ, Mozsary PG. Rigid endosseous implant utilized as anchorage to protract molars and close an atrophic extraction site. Angle Orthod. 1990; 60: 135-152.

20. Costa A, Raffaini M, Melsen B. Miniscrews as orthodontic anchorage: a preliminary report. Int $J$ Adult Orthod Orthognath Surg. 1998; 13: 201-209.

21. Melsen B, Costa A. Immediate loading of implants used for orthodontic anchorage. Clinic Orthod Res. 2000; 3: 23-28.

22. Wu J, Bai YX, Wang BK. Biomechanical and histomorphometric characterizations of osseointegration during mini-screw healing in rabbit tibiae. Angle Orthod. 2009; 79: 558-563.

23. Huja SS, Litsky AS, Beck FM, Johnson KA, Larsen PE. Pullout strength of monocortical screws placed in the maxillae and mandibles of dogs. Am J Orthod Dentofacial Orthop. 2005; 127: 307-313. 